\title{
¿QUIÉN ES EL SUJETO DE DERECHOS HUMANOS? DISCUSIÓN ENTRE MARXISMO Y POSFUNDACIONALISMO
}

\section{WHO IS THE SUBJECT OF HUMAN RIGHTS? \\ DISCUSSION BETWEEN MARXISM AND POSTFUNDACIONALISM}

\author{
Omar Santiago Herrera Rodríguez ${ }^{1}$ \\ Universidad de Costa Rica, Sede de Occidente \\ omar.herrera@ucr.ac.cr
}

Recibido: 4 de julio 7 del 2017 / Aceptado: 6 de setiembre 9 del 2017.

Publicado: 7 de noviembre del 2017

Resumen: El presente artículo examina las respuestas brindadas por Karl Marx y la teoría post fundacionalista sobre el problema de quién es el sujeto de derechos humanos, con el objetivo de desarrollar una lectura marxista que permite defender derechos humanos, al mismo tiempo que criticar la lectura politicista de la teoría post fundacionalista.

Palabras clave: derechos humanos, ciudadanía, humano.

Summary: The present article examines the answers provided by Karl Marx and postfundacionalist theory about the problem of who is the subject of human rights, with the objective to develop a marxist reading that allows defend human right, at the same time critizing the "politicista" reading of postfundacionalist theory.

Keywords: Human Rights, citizenship, human.

1 Máster en Estudios Latinoamericanos con énfasis en Cultura y Desarrollo por la Universidad Nacional de Costa Rica, licenciado en Trabajo Social por la Universidad de Costa Rica, bachiller en Filosofía por la Universidad de Costa Rica. Docente de la carrera de Trabajo Social en la Universidad de Costa Rica, Sede de Occidente. 


\section{Volver a lo que se ha querido dejar de lado}

En el año 2004, el filósofo Jacques Rancière publicó un artículo intitulado Who is the Subject of the Rights of Man?; más allá de la respuesta brindada por él, y que examinaré aquí, la pregunta a mi entrever toca el nudo gordiano de la cuestión sobre derechos humanos.

El sustantivo compuesto derechos humanos indica explícitamente que su sujeto son los humanos; sin embargo, el debate desarrollado desde el siglo XIX por Marx ya ponía en cuestionamiento quién es ese humano. De igual manera, el desarrollo posterior, realizado en el siglo XX por Hanna Arendt, reavivará el problema sobre el cual la teoría postfundacionalista ha tomado su punto de partida, como señala Cristobo (2014). En los tres casos, la discusión versa sobre la relación ciudadano-humano, generando puntos de encuentro y desencuentro a la hora de dar una respuesta final, como demostraré.

Lo llamativo del caso es que tanto Rancière (2004) como Žižek (2011) señalan, respectivamente, que no tiene ningún sentido retomar la discusión desarrollada por Marx en torno a esta cuestión. No obstante, esta omisión nunca es justificada por ninguno de los autores en sus artículos respectivos.

De esta manera, una vez reconstruida la lectura de Arendt y Marx sobre el problema del sujeto de derechos humanos, abordaré la crítica postfundacionalista a la tesis de Arendt y su actualización para, después, desde una relectura marxista a la tesis de Marx, demostrar que 1) las tesis postfundacionalistas tienen más en común con este que con Arendt, pero que al enmarcar su desarrollo en una discusión politicista pierden un importante espectro de crítica y comprensión del problema y 2) a pesar de la posición tomada por Marx sobre derechos humanos, desde la propia propuesta del autor es posible generar una defensa de estos sin renunciar a la crítica marxista.

\section{El problema del humano para Hanna Arendt}

La discusión de Arendt, al igual que la de Marx, se encuentra enmarcada en la relación que se establece entre el humano y el ciudadano a la hora de definir quién es el sujeto de derechos humanos. Aunque el problema es el mismo, la lectura de ambos es totalmente distinta, como mostraré en este y el próximo apartado. 
La situación de las minorías y de los apátridas después de la I Guerra Mundial muestra a Arendt (2015) que un individuo desprovisto de su condición de ciudadanía, en cuanto no perteneciente a ninguna comunidad política, no poseía a la vez ningún mecanismo que pudiera asegurarle o protegerle sus derechos, lo anterior a pesar de su proclamada inalienabilidad.

Tal como señala Gallardo (2007), desde el punto de vista operativo, solo existen los derechos que pueden reclamarse jurídicamente, es decir, en circuitos judiciales que presuponen una determinada forma de organización de la vida social-política (el Estado moderno de derecho) y, por ende, una determinada condición de existencia en esta forma de organización: la ciudadanía.

A pesar de la inalienabilidad formal con que los derechos humanos fueron revestidos políticamente, la ausencia de la condición de ciudadanía y de la plataforma política que sustenta a esta hacía de aquellos individuos, cuya condición era la de meramente humanos, no ser sujetos de derechos humanos ${ }^{2}$. El efecto producido durante la I Guerra Mundial sobre los apátridas y las minorías mostraría, con total claridad, esta contradicción.

Si derechos humanos, y por tanto la condición de humanidad, están por encima y antes de toda autoridad política y su sistema de leyes, son estos últimos los que deben deducirse y restringirse a derechos humanos. La soberanía del hombre [sic] queda entredicha, dado que los meramente humanos son incapaces de demandar para sí sus derechos, porque no existe ninguna institución política que los proteja.

De esta manera, la inexistencia de una comunidad política y su respectivo cuerpo de normas, leyes e instituciones torna inadmisible la idea de que los derechos humanos son inherentes a la condición de ser humano; por el contrario, demuestran que la ciudadanía y la existencia de un cuerpo político-institucional, que les dé sostenibilidad y reconocimiento, son las condiciones necesarias para la efectividad de estos en las sociedades modernas.

Por tanto, la tesis de Arendt (2015) puede resumirse en que el ser humano no es la condición sine qua non para garantizar el acceso y protección a sus derechos humanos, sino la ciudadanía que lleva como condición de posibilidad la existencia del Estado moderno de derecho.

2 Habría que señalar aquí que la crítica de Arendt (2015) es limitada en la medida que alcanza tan solo al fundamento provisto por la tesis iusnaturalista de Derechos Humanos. 
Finalmente, como puede apreciarse bajo esta línea de análisis, derechos humanos pierde toda potencialidad universal, puesto que lo universal de la humanidad es reducido a lo particular de cada Estado nación. De tal modo, Arendt genera una indistinción irresoluble en su propia reflexión entre derechos ciudadanos y derechos humanos.

Esta será la crítica de la cual parte la tesis postfundacionalista que abordaré en la tercera parte de este trabajo. Ahora bien, la crítica de Marx a derechos humanos nace igualmente de la relación ciudadanía-humanidad, sin embargo, como mostraré, en esta no existe la división en la que incurre Arendt.

\section{El problema del humano para Karl Marx}

Recién indiqué que Arendt toma un derrotero distinto al de Marx sobre la relación entre ciudadanía y humanidad, al partir del supuesto de la moderna división entre sociedad civil y sociedad política, ya teorizada ampliamente por Hegel (2010), quien señala que la relación entre ambas dimensiones de la eticidad radica en que, aun cuando el fin de la sociedad civil es egoísta, la realización y el bienestar de los individuos que la componen únicamente es posible mediante la conexión con el resto de los individuos que conforman la comunidad política o Estado (momento universal).

Estas dos dimensiones, que en Hegel aparecen reconciliadas, en Marx (2009) se muestran conflictuadas y su reconciliación tan solo es producto de la imaginación: "Por el contrario, en el Estado, donde el hombre vale como un ser genérico, es el miembro imaginario de una soberanía imaginaria, se le ha despojado de su vida individual real y se le ha dotado de una generalidad irreal." (Marx, 2009, p. 137). El ser humano lleva una doble vida, señala Marx (2009): mientras en la comunidad política se considera un ser comunitario, en la sociedad burguesa considera a todos los demás como medios, degradándose a sí mismo como medio para los otros.

Precisamente, la crítica de Marx parte de esta escisión del individuo en dos dimensiones que persiguen fines opuestos, cuya convivencia es posible en las sociedades modernas a partir de un ocultamiento: el fetiche de la ciudadanía, el cual, a través del derecho moderno, permite que la igualdad y 
la libertad formal coexistan con las formas más degradantes de desigualdad y explotación real.

Por eso, si el citoyen es el sujeto de la sociedad política, el homme es el sujeto de la sociedad civil (el individuo burgués). De ahí que Marx denuncia el carácter despolitizado con que el individuo burgués se presenta a sí mismo en la sociedad: como hombre no político o natural, haciendo que su dominio se presente como natural.

En realidad, el problema del homme no es exclusivo de derechos humanos, sino de la racionalidad que subyace y fundamenta al derecho moderno burgués, desde la cual la Declaración ${ }^{3}$ fue pensada y constituida. Lo anterior puede apreciarse en la concepción de ser humano sostenida por Locke (2012) en los $\$ 4, \S 26$ y $\$ 27$. El individuo de Locke se caracteriza por ser libre, igual a los otros, racional y propietario. En otras palabras, la crítica de Marx a derechos humanos es más profunda en cuanto se encuentra instalada en la crítica del sistema capitalista y su forma predominante de organización de la vida social-política: el Estado moderno de derecho burgués.

Ahora bien, la cuestión central radica en cómo el burgués llegó a constituirse y proyectarse a sí mismo como el homme en general y, por ende, cómo sus derechos se constituyeron y proyectaron como los de los humanos en general. Este falso universal del proyecto burgués parte de la distorsión de la idea de emancipación, puesto que la burguesía presenta su emancipación política respecto de las antiguas formas de dominación feudales, como si esta fuese una emancipación universal.

Tal distorsión es evidenciada por Marx (2009) al visualizar los verdaderos alcances del derecho burgués, el cual no elimina la religión ni la propiedad, sino que, en su lugar, declaró la libertad religiosa y la libertad de propiedad ${ }^{4}$.

Así también, al examinar los cuatro elementos principales que componen la Declaración (liberté, propriété privée, égalité y sûreté), encuentra en ellos el retrato del individuo egoísta, potencial agresor y agredido en sus relaciones con el resto de la comunidad política, donde la seguridad sirve

3 Declaración de los Derechos del Hombre y del Ciudadano, 1789.

4 Llama la atención que, aunque Žižek (2011) optó por dejar de lado la crítica realizada por Marx, su primera línea de discusión en torno al cuestionamiento de la libertad de elegir en las sociedades liberales-capitalistas es igual a la reflexión de Marx. 
para la conservación de su propiedad (para Locke la propiedad precisamente remite a la vida, la libertad y las posesiones).

De esta manera, aunque Arendt y Marx comparten el mismo punto de llegada, el contenido es totalmente distinto. Mientras la primera encuentra que la ciudadanía es la condición de posibilidad para demandar y proteger los derechos humanos, Marx ve en la ciudadanía "el simple medio para la conservación de estos llamados derechos humanos" (p. 150), puesto que el citoyen es un mero servidor del homme burgués.

Lo anterior porque los derechos humanos protegen los intereses y propiedades del hombre egoísta, y brindan la seguridad necesaria para que este pueda reproducir su orden de dominación mediante el disfraz de la supuesta genericidad que estos expresan. Ahora bien, la dificultad principal de la posición de Marx es su unilateralidad respecto del Derecho y, más puntualmente, respecto de Derechos Humanos, como desarrollaré en el próximo apartado.

Vale por ahora indicar que para Marx (2010) el Estado constitucional encuentra un límite que él mismo no vuelve explícito en este momento de desarrollo de su obra, pero que aparecerá con total claridad en sus escritos de madurez: el capitalismo necesita explotar la fuerza de trabajo de una gran parte de la población y conformar un excedente de trabajadores para sostener el control de su particular régimen de empleo-explotación, a la vez que concentra privadamente los medios de producción en un reducido sector de la población.

El Estado puede generar políticas paliativas y contenedoras de las contradicciones generadas por esta dinámica de acumulación privada del capital; no obstante, no puede generar ninguna política que atente contra dicha dinámica. El imperio de la ley en la tierra se sostiene porque existe el imperio del capital en el cielo.

¿Qué papel juega entonces lo formal o el Derecho para Marx? El de cómplice de lo real, y es por eso que la relación entre ambas no es unilateral sino dialéctica. La desigualdad de lo real es enmascarada por la igualdad formal; para que el trabajador pueda ser más y mejor explotado es necesario que no muera en el proceso, y es aquí donde el derecho del citoyen cobra su lugar en el impedimento de la muerte; mas no en la eliminación de la relación de explotación entre el burgués y el trabajador. 
Aunque la crítica de Marx apunta al núcleo de la contradicción del capitalismo y el Estado moderno, como cualquier contradicción, su proceso no es unilateral o unívoco. Las tensiones que las fuerzas sociales en conflicto desarrollan hacen del Estado burgués, y de Derechos Humanos, formaciones sociales más complejas. Esta complejidad de la política es lo que la teoría postfundacionalista agrega al debate en torno a la cuestión de Derechos Humanos y de su sujeto.

\section{Críticas posfundacionalistas a derechos humanos}

Rancière (2004) sintetiza la propuesta de Arendt bajo el siguiente enunciado: "los Derechos del Hombre son los derechos de aquellos que no tienen los derechos que tienen y tienen los derechos que no tienen." (Rancière, 2004, p. 302). Este juego de palabras refleja precisamente el problema que Arendt identifica: en la condición de mera humanidad los seres humanos dejan de tener derechos. No obstante, al formular la cuestión de esta manera, Rancière (2004) encuentra que Arendt provoca una despolitización de los derechos humanos y de la condición de humanidad.

La rígida división en la que Arendt incurre, entre sociedad civil y sociedad política, construye una dimensión o espacio más allá de la política. Paradójicamente, el intento de denuncia política de la situación de los apátridas y minorías de Arendt conduce a la despolitización de los asuntos de poder y represión visualizados al situarlos en una esfera de excepción que no es política.

Ahora bien, la crítica de Rancière alcanza, sin pretenderlo, la posición defendida por otro teórico postfundacionalista: Étienne Balibar. Este último hereda y continúa la discusión desarrollada por Arendt, examinando cómo, en las dos tradiciones explicativas de la fundación democrática de los derechos del ciudadano (la liberal-individualista (Locke) y la republicana-comunitarista (Rousseau)), está presente una tesis antropológica que a su vez contiene una antinomia, lo que él denomina "the negative dimensions of the democratic constitution" (p. 320).

Balibar (2004) señala que existen formas de exclusión (de la condición de ciudadanía y de la condición de humanidad misma) que "son inherentes a todo procedimiento de definición de la importancia, intrínsecamente 
política, de la universalidad de los derechos humanos" (p. 320). Tales formas están presentes tanto en Rousseau (la coerción para ser libre) como en Locke (la exclusión del criminal), lo cual lleva al autor a concluir que es la ciudadanía la que funda los derechos humanos y no al revés; en cuanto, estas formas de exclusión contenidas en la universalidad de los derechos humanos niegan a individuos específicos en condiciones específicas su acceso y capacidad de derechos, una vez que han sido excluidos de la comunidad política.

De esta manera, la condición de humanidad se encuentra en un momento pre-político, cuya consecuencia es despolitizadora; por el otro lado, en la condición de ciudadanía estaría presente la real capacidad de politizar la vida social y de efectivizar los derechos humanos.

En ambos casos, encontramos una dimensión despolitizada de la vida de los seres humanos: la mera vida. Ahora bien, Rancière (2004) reconoce que en Agamben (2013) existe un esfuerzo importante de superación de la tesis de Arendt, al identificar que la política se ha configurado en una biopolítica en cuanto subsume la bios en la zoe.

Si el proceso es así, la propuesta de Agamben intenta combatir dicho efecto despolitizador generado por la visión de Arendt, al demostrar que no hay más oposición entre el poder soberano y el biopoder, pues ambos son lo mismo, con lo que se puede defender que las dos esferas, abismalmente distanciadas por Arendt (la condición de humano y la condición de ciudadano), en realidad se encuentran articuladas por Agamben.

A pesar de lo anterior, Rancière (2004) señala que las posiciones de Arendt y Agamben conducen al mismo punto de llegada: "Sin embargo, quiero suponer que la suspensión radical de la política, en la expresión de la vida expuesta, es la última consecuencia la posición de Arendt en la estructura política, o su intento por preservar la política de contaminarse de una vida particular, social, apolítica." (p. 301) Es aquí donde comienza la propia posición del autor.

A diferencia de Arendt y Balibar: "Los Derechos del Hombre no son los derechos de un sólo sujeto, que al mismo tiempo sería el portador de los mismos y que sólo podría usar aquellos que él o ella posean” (Rancière, 2004, p. 302), sino, más bien, "El sujeto de derecho es el sujeto o más precisamente el proceso de subjetivación, que conecta el intervalo entre las dos formas de existencia de estos derechos." (Rancière, 2004, p. 302) 
Estas dos formas son la formal y la real. Según Rancière (2004), derechos humanos son derechos escritos (formales), pero este carácter no es un simple predicado de algo que no existe en lo real. Por el contrario, si en lo real no se efectiva X o Y derecho, derechos humanos permiten verificar el poder de la inscripción escrita y, por tanto, se convierten en los derechos de quienes hacen algo de ellos.

De ahí que derechos humanos sea un proceso de subjetivación política, puesto que tanto el hombre como el ciudadano son sujetos políticos, por ende, no existe disyunción entre ambos, sino más bien la posibilidad de generar una apertura para un intervalo de subjetivación política, que cuestiona y procura habilitar la cualificación política de aquellos que son descalificados o negados de la vida política.

Esta es la propuesta que rescata Žižek (2011) al mostrar que derechos humanos, en lugar de ser prepolíticos, son en realidad el ámbito de politización en el que los agentes políticos afirman su disención (poner dos mundos en el mismo mundo) consigo mismos, al asumirse como el agente de universalidad de lo social siendo un particular. De esta manera, es recuperada la universalidad de derechos humanos como derechos metapolíticos, evitando toda reducción de la política a la negociación de intereses particulares y, por tanto, la pérdida de la política.

En realidad, la agencialidad unificante o articulante, que tanto Rancière como Žižek señalan, había sido esbozada por Alain Badiou en el año 2000, en un encuentro en la casa de las Madres de Plaza de Mayo, Argentina, al hacerse las siguientes tres preguntas: ¿qué es el hombre?, ¿qué es la humanidad? ¿quién tiene derechos? Contrario a los derechos humanos como ideología del capitalismo globalizado, que coloca al hombre [sic] de los derechos humanos como víctima, Badiou (2000) defiende la posición antagónica: el hombre de derechos humanos es el que 1) a pesar del sufrimiento sigue en pie y 2) el que sabe que el mundo puede cambiar, por tanto, sabe que lo imposible es posible.

Lo llamativo del caso es que la posición de Badiou, Rancière y Žižek en realidad no se encuentra en contra de la de Marx, y es posible que, de haber examinado con atención lo planteado por este, habrían descubierto sus puntos de encuentro y continuidad. En efecto, la conclusión que coloca la ciudadanía como medio para la conservación del homme burgués es 
unilateral, porque el propio derecho moderno no es un mero instrumento de dominación y conservación del ordenamiento vigente, tal como había sido considerado por Engels (2005) $)^{5}$.

La lucha por derechos pone en evidencia lo real, en la medida en que lo formal es una manera de visibilidad que brinda recursos de verificabilidad y exigencia. Aquí Rancière y Žižek completan algo que Marx entrevió y no desarrolló con claridad, pero que es posible identificar en su obra: "En cambio en el Poder Ejecutivo, por ejemplo, la misma mentira tendría que disolverse inmediatamente o convertirse en una verdad" (Marx, 2010, p. 142, subrayado mío).

Si bien Marx colocó la ciudadanía, y por tanto el derecho como simple medio de sostenimiento del orden de dominación y explotación del mundo real, deja abierta la puerta de la materialización real de lo formal, lo cual ocurre en la medida que el Estado es un campo de condensación de fuerzas sociales y no un simple instrumento de la burguesía.

Pero para que esta materialización de lo formal en lo real, o conversión de la mentira en verdad, sea auténticamente universal, el derecho moderno y, por tanto, derechos humanos, son insuficientes, por sí mismos, porque se encuentran restringidos o demarcados por los límites dispuestos en una estructura más amplia que estos: el sistema de dominación capitalista. La crítica de Rancière se queda corta respecto del problema, pues permanece en el campo de la política sin abordar la cuestión de la economía política.

Por ello, es necesario recolocar el problema en otra esfera: la de la emancipación humana; aquella por la cual Marx se inclinó para abordar el problema de derechos humanos, o como él mismo señaló en otro de sus escritos, solo en la sociedad comunista "podrá superarse el estrecho horizonte del derecho burgués” (Marx, 2012, p. 662), en otras palabras, donde la mentira puede convertirse en verdad.

Este nuevo encuadre me lleva una vez más a la cuestión de quién es el sujeto de derechos humanos y a añadir, además, si, a partir de una resignificación del human, derechos humanos obtiene un lugar en los procesos revolucionarios por la emancipación humana.

5 Al respecto, el autor señala: "Sin embargo, por excepción, hay períodos en que las clases en lucha están tan equilibradas, que el poder del Estado, como mediador aparente, adquiere cierta independencia momentánea respecto de una y otra" (Engels, 2005, p. 222). 


\section{Derechos humanos y la emancipación humana}

Existe una imprecisión importante en el acercamiento de Arendt a la cuestión de los apátridas y grupos minotarios, pues, donde ella ve mera humanidad, en realidad hay nuda vida. Este concepto (antecedente teórico del homo sacer de Agamben), autoría de Benjamin, contribuye al cuestionamiento de la falsa justificación que hace de la nuda vida algo más importante que la vida de un animal o un vegetal.

Dicha justificación aparece en el momento en el que se apela al carácter sagrado de la vida humana. Sin embargo, como señala Benjamin (2016): "El hombre no coincide en modo alguno con la mera vida que es la suya; tampoco con la mera vida en él, ni con ningún estado o propiedad; ni coincide tampoco, tan siquiera, con la unicidad de su persona." (p. 2014) En realidad, el mero humano, al que Arendt hace referencia, no es el ser humano ni la vida humana.

Esta variación interpretativa de la propuesta de Arendt profundiza la resolución de Rancière (2004), y nos conduce a una nueva lectura de la crítica de Marx. En efecto, el ser humano no es un concepto opuesto a los derechos reales del ciudadano, y esto es precisamente porque, como señala Benjamin, la nuda vida no coincide con el ser humano.

Sin embargo, ¿qué es la nuda vida?, es la vida sacralizada y, por ende, una vida que no es humana en el sentido que Benjamin, Agamben y Rancière comprenden, porque socio-históricamente ha sido producida como no-humana, y por eso se encuentra sujeta a su violación sin perjurio. Por esta razón, no es al humano al que hay que dar un estatuto político, como lo hace Rancière, sino al no-humano.

En realidad, este problema del no-humano puede deducirse con facilidad de la reflexión de Marx. Si el homme burgués se ha afirmado como el parámetro de delimitación de lo humano, todo lo no-burgués es por tanto no-humano. La cuestión aquí es la disputa por el estatuto o condición de humanidad, la cual es potencialmente política.

El modo de producción capitalista niega la condición de humanidad del proletariado (o sectores populares), una vez que la burguesía se apropia de los medios de producción. El obrero queda sujeto a la arbitrariedad del burgués, con el fin de poder obtener los medios para su reproducción vital, 
pues lo que está en juego es su vida. Aún cuando el obrero pueda tener su condición de ciudadanía, esta no le garantiza dichos medios o recursos necesarios para continuar viviendo, pues tan solo es libre de trabajar, pero en condiciones mediante las que prevalece la explotación contra él.

La cuestión de la privatización de los medios de producción y reproducción de la vida en sociedad es un asunto de economía política, no simplemente de la política. Por eso, la emancipación política no es el mecanismo a través del cual se obtiene la posibilidad real de desarrollo de la propia vida social; sino que el horizonte se encuentra en una auténtica emancipación humana. En este aspecto, la crítica posfundacionalista que he demarcado se queda corta para discutir el papel radical que derechos humanos puede tener en el proceso de emancipación humana.

Veamos la anotación que Marx (2009) realiza sobre la cuestión de la emancipación humana:

Sólo cuando el hombre individual real recupera en sí al ciudadano abstracto y se convierte como hombre individual en ser genérico, en su trabajo individual y en sus relaciones individuales, sólo cuando el hombre ha reconocido y organizado sus forces propres como fuerzas sociales y cuando, por tanto, no separa ya de sí la fuerza social en la forma de fuerza política, sólo entonces se lleva a cabo la emancipación humana. (Marx, 2009, p. 155)

Recuperación del mundo humano en cuanto ha sido apropiado y distorsionado ideológicamente por la burguesía, divulgando y promoviendo una humanidad de seres libres e iguales, cuando, en realidad, la libertad e igualdad estaban reservadas solo para un sector social. Por eso, los no-humanos (los sectores populares) deben recuperar para sí el mundo humano, su humanidad.

Marx apela a la articulación real del ciudadano abstracto (lo formal) y del hombre individual (lo real), convertidos ahora en un ser genérico: el ser humano, que articula las fuerzas políticas con el conjunto de las sociales (la falsa escisión entre sociedad civil y sociedad política, entre economía y política es resquebrajada) para construir un auténtico proyecto de emancipación humana.

El homme no es ya el burgués, sino los sectores sociales que luchan por esta auténtica emancipación humana y, por tanto, se autoconstituyen 
como humanos. Consecuentemente, ante esta resignificación del concepto humano, derechos humanos se convierten en los de aquellos que luchan por el reconocimiento de su condición de humanidad y por la construcción de las condiciones reales para dicho reconocimiento.

Su campo de racionalidad e eficacia, por tanto, excede los límites del derecho burgués y de la racionalidad jurídica, como pretende encasillar de forma simple la crítica "marxista" desarrollada por Tonet (2002), esto porque el fundamento de derechos humanos se encontraría en el conflicto inaugural de las sociedades modernas, como indica Gallardo (2008), así como su en eficacia.

La eficacia de derechos humanos se sigue de las movilizaciones de los grupos sociales que luchan por legitimar su experiencia de vida social como auténticamente humana, y fraguarla en el conjunto de instituciones sociales, económicas, culturales y político-jurídicas, pudiendo configurar un ethos cultural que sirva como plataforma de sostenibilidad.

Son los movimientos sociales y sus luchas los que generan, mediante la transformación de las instituciones vigentes, reales transferencias de poder que "potencien al sujeto humano en la familia, la escuela, en las relaciones económicas (propiedad/trabajo, apropiación), en la sexualidad, en la producción espiritual, cotidianidad, etc., o sea en todos los espacios y lógicas sociales" (Gallardo, 2008, p. 65).

Precisamente, derechos humanos, en tanto ethos y horizonte que despliega acciones diversas de los movimientos sociales, que luchan por su emancipación de las distintas estructuras de dominación que les oprimen y cosifican, se articulan como uno de los múltiples mecanismos para el desarrollo de los procesos de emancipación humana expresados por Marx.

Por tanto, derechos humanos se vinculan con un proyecto de emancipación universal humana, por cuanto busca la reconfiguración de los patrones de poder producidos y reproducidos por el sistema capitalista; para poner en su lugar nuevas formas de organización de la vida social humana.

Se trata pues, como señalaba Marx, de constituir una sociedad que genere las condiciones y estructuras donde la mentira pueda convertirse en verdad, a partir de la transformación del conjunto de las estructuras del orden social vigente, y donde los seres humanos tomen, conscientemente, 
su proceso de autoconstitución mediante el acceso universal de los medios de producción y el goce de los frutos obtenidos por su trabajo.

\section{Conclusión}

He demostrado que existe un punto de encuentro entre la teoría marxista y la teoría posfundacional en torno al sujeto de derechos humanos. Dicho sujeto conlleva la lucha y exigencia por su condición o estatuto de humano que en el ámbito de lo formal se expone, pero en el de realidad se le niega. Es mediante su acción política que rompe con el imaginario moderno de la distancia entre ambos mundos o dimensiones, a la vez que persigue la materialización real de sus derechos escritos.

Sin embargo, la discrepancia entre ambos planteamientos surge en el momento en que la posición de los autores posfundacionalistas se limita a la crítica política, en lugar de considerar la economía política e identificar que, en el marco de las sociedades capitalistas, es imposible la real y general efectivización de derechos humanos.

De esta manera, el sujeto de derechos humanos no solo persigue la efectivización de estos, sino la radical transformación de las condiciones sociales, económicas, políticas y culturales en las cuales estos se desenvuelven y desarrollan. Únicamente apropiándose de modo consciente del conjunto de condiciones que mediatizan la producción y reproducción humana, el sujeto de derechos humanos los torna efectivos.

\section{Referencias}

Agamben, G. (2013). Homo Sacer. El poder soberano y la nuda vida. Madrid: Pre-textos. Arendt, H. (2015). Los orígenes del totalitarismo. Madrid: Alianza.

Badiou, A. (2000). La ética y la cuestión de los derechos humanos. Acontecimiento, 19(20), 1-7.

Balibar, E. (2004). Is a Philosophy of Human Civic Rights Possible? New Reflections on Equaliberty. The South Atlantic Quarterly, 103 (2/3), 311-322. Recuperado de https:// doi.org/10.1215/00382876-103-2-3-311

Benjamin, W. (2016). Hacia la crítica de la violencia. En: W. Benjamin (Ed.), Obras, Libro II. Vol. 1. (183-206). Madrid: Abada.

Cristobo, M. (2014). Variaciones posmarxistas sobre el "derecho a tener derechos". Hannah Arendt, 12, 145-166.

Engels, F. (2005). El origen de la familia, de la propiedad privada y del Estado. Madrid: Mestas. 
Gallardo, H. (2007). Sobre el fundamento de los derechos humanos. Revista de Filosofía de la Universidad de Costa Rica, XLV (115/116), 9-24.

Gallardo, H. (2008). Teoría crítica: matriz y posibilidad de Derechos Humanos. Murcia: Ed. David Sánchez Rubio.

Hegel, W. (2010). Lineas fundamentales de la Filosofía del Derecho. En: W. Hegel II (11-312). Hegel II Líneas fundamentales de la Filosofía del Derecho. Lecciones de la Filosofía de la Historia (11-312). Madrid: Gredos.

Locke, J (2012). Segundo tratado sobre el gobierno civil. Madrid: Alianza.

Marx, K. (2009). Sobre la cuestión judía. Iztapalapa: Anthropos.

Marx, K. (2010). Crítica de la Filosofía del Estado de Hegel. Madrid: Biblioteca Nueva.

Marx, K. (2012). Crítica al programa de Gotha. En: K. Marx, Marx (651-675). Madrid: Gredos.

Rancière, J. (2004). Who Is the Subject of the Rights of Man? The South Atlantic Quarterly. 103 (2/3). 297-310.

Tonet, I. (2002). Para além dos direitos humanos. Revista Novos Rumos, 37, 63-72.

Žižek, S. (2011). En contra de los derechos humanos. Revista Suma de Negocios, 2(2), 115-127. 